\title{
Variation in surgical treatment advice for women with stress urinary incontinence: a study using clinical case vignettes
}

\author{
Jil Billy Mamza ${ }^{1} \cdot$ Rebecca Geary $^{1} \cdot$ Dina El-Hamamsy ${ }^{2} \cdot$ Ipek Gurol $^{1} \cdot$ Jonathan Duckett $^{3} \cdot$ Tahir Mahmood $^{4}$. \\ Ash Monga $^{5} \cdot$ Philip Toozs-Hobson $^{6} \cdot$ Andrew Wilson $^{7} \cdot$ Douglas Tincello $^{7} \cdot$ Jan Van der Meulen ${ }^{1}$
}

Received: 25 November 2019 / Accepted: 26 March 2020 / Published online: 6 April 2020

(C) The Author(s) 2020

\begin{abstract}
Introduction The aim of this study was to determine how recommendations of gynaecologists on surgical treatment for stress urinary incontinence (SUI) were influenced by patient characteristics.

Methods Two hundred forty-five gynaecologists in the UK fully responded to an online questionnaire including 18 vignettes describing 7 clinical characteristics of women with SUI (age, body mass index, SUI type, previous SUI surgery, frequency of leakage, bother, physical status). The gynaecologists scored recommendations for surgery ranging from 1 'certainly not' to 5 'certainly yes'. Mean scores were used to calculate the relative impact ('weight') of each clinical characteristic. Latent class analysis was used to distinguish groups of gynaecologists with a particular practice style because they responded to the patient characteristics captured in the case vignettes in a similar way.

Results The gynaecologists' overall average recommendation score was 2.9 (interquartile range 2 to 4 ). All patient characteristics significantly influenced the recommendation scores ( $p$ always $<0.001)$ but their impact was relatively small. SUI type was most important (weight 23\%), followed by previous SUI surgery (weight 21\%). Latent class analysis identified five groups of gynaecologists with practice styles that differed mainly with respect to their mean recommendation score, ranging from 1.3 to 4.0. Conclusions Surgical treatment advice in response to case vignettes was only minimally influenced by patient characteristics. There were five groups of gynaecologists whose inclination to recommend surgical treatment varied. This suggests that there is lack of consensus on the role of surgery as a treatment for SUI. A considerable number of gynaecologists were reluctant to recommend surgery.
\end{abstract}

Keywords Case vignettes $\cdot$ Decision-making $\cdot$ Female urinary incontinence $\cdot$ Surgical treatment

Douglas Tincello and Jan van der Meulen Joint senior authors

Electronic supplementary material The online version of this article (https://doi.org/10.1007/s00192-020-04295-4) contains supplementary material.

Jan Van der Meulen

Jan.vanderMeulen@1shtm.ac.uk

1 Department of Health Services Research and Policy, London School of Hygiene \& Tropical Medicine, London WC1H 9SH, UK

2 University Hospitals of Leicester NHS Trust, Southampton, UK

3 Medway NHS Foundation Trust, Kent, UK

4 NHS Fife Victoria Hospital, Scotland, UK

5 University Hospital Southampton NHS Foundation Trust, Southampton, UK

6 Birmingham Women's and Children's NHS Foundation Trust, Birmingham, UK

7 Department of Health Sciences, University of Leicester, Leicester, UK

\section{Introduction}

Surgical treatments for stress urinary incontinence (SUI) are offered when conservative treatments are ineffective [1]. Over the last 10 years, there have been increasing concerns about the long-term risks of synthetic mid-urethral mesh sling insertion, by far the most commonly used surgical procedure treatment for SUI [2]. As a result, the frequency of mid-urethral mesh sling insertions has rapidly declined worldwide, with a reduction by about 50\% between 2008 and 2017 in the UK [3], which highlights a major change in surgical practice.

The decision to recommend surgery is complex and many factors need to be considered, including the patient's past management, comorbidities and the impact that the SUI has on quality of life. Recent UK guidelines emphasize that treatment decisions need to focus on providing a woman with the best outcomes from her own individual perspectives [4]. 
To investigate in a systematic and quantitative way how all these factors influence the decision to recommend surgical treatment, we carried out a national survey of gynaecologists in the UK with a specialist interest in urogynecology. The survey included a series of written case simulations ('clinical case vignettes') that describe a number of patient characteristics, including the type of urinary incontinence (UI) and severity of the SUI. The gynaecologists were asked to indicate whether they would recommend immediate surgical treatment for each of the patients described in these vignettes.

Surveys based on clinical case vignettes are increasingly being used as a cost-effective approach to study how clinicians make decisions on the diagnosis and treatment of patients [5], for example, to study what factors influence decisions to use neuromodulation for patients with refractory idiopathic overactive bladder syndrome [6].

In the current study, we used an experimental approach which is sometimes referred to as 'conjoint analysis'. This type of analysis is based on the notion that people make complex decisions by combining information from various sources ('cues') [7]. The importance ('weight') that a decision-maker places on each cue can be studied by measuring the joint effects of the cues on decisions made in response to a series of hypothetical decisions [8]. In this way, we could estimate the extent to which the treatment recommendations of the gynaecologists were influenced by the women's clinical characteristics. We also used latent class analysis to explore to what extent we could classify the gynaecologists into mutually exclusive groups with different 'practice styles', based on the pattern of their treatment recommendations in response to the characteristics described in the case vignettes in a similar way [9].

\section{Materials and methods}

\section{Survey}

In 2017 we carried out an online survey of all members of the British Society of Urogynaecology and members of the Royal College of Obstetricians and Gynaecologists who had indicated they had an interest in urogynecology. We invited 1139 clinicians practicing in the UK, including senior trainees. These clinicians are practising gynaecologists and urogynecologists. All of them can be expected to be involved in making decisions about surgical treatment and most of them can be expected to perform surgery themselves. Data were collected with a webbased programme and a link to the survey was emailed to potential participants. Three reminder emails were sent in the 1-month period following the first email.

The survey consisted of an information screen providing a brief description of the project, questions on the surgeons' characteristics, a page providing additional information and a number of clinical assumptions (see below) that the gynaecologists needed to make when responding to the clinical case vignettes (for the full survey, see Table S1 in Supporting Information).

\section{Development of the clinical case vignettes}

A three-stage approach was followed to determine the specific patient characteristics and their relevant levels to be included in the clinical case vignettes. In the first stage ('item identification'), a non-systematic literature search was carried out to identify patient characteristics associated with the short- and long-term outcome of SUI surgery. One of the authors (JM) independently identified potentially relevant preoperative patient characteristics. Another author (DE) reviewed the list of characteristics to ensure that terminologies were consistent with clinical practice in the UK. Four senior clinical experts (DT, JD, AM and PTH) were given the opportunity to add to this long list if they felt that important characteristics were missed.

In the second stage ('item reduction'), seven potential characteristics were selected that were considered most important: age, body mass index (BMI), type of UI, defined as pure SUI, stress pre-dominant mixed urinary incontinence (MUI) and MUI, previous SUI surgery, leakage, bother and physical status. Also, the relevant levels for each of these characteristics were determined, aiming to create maximum difference between the levels for each characteristic while ensuring that the clinical profiles captured in the case vignettes were relevant and realistic (Table 1 and Box).

Box: Example of a clinical case vignette

A 55-year old woman presents with symptoms of mixed incontinence. She leaks several times a day. She says that her UI condition is affecting. her daily activities and is a serious problem for her. Her BMI is $36 \mathbf{~ k g} / \mathbf{m}^{2}$.

Previous gynaecological history includes mid-urethral tape. She is ASA grade 2.

Would you recommend that this patient has surgical treatment now?

$\square$ Certainly yes

$\square$ Probably yes

$\square$ Not sure

$\square$ Probably not

$\square$ Certainly not

PLEASE ASSUME THAT:

PATIENTS

- have been referred by their GP for further assessment

- have completed all conservative and behavioural treatments (e.g. frequency volume charts, pelvic floor exercises, etc.) without benefit

RESULTS OF EXAMINATION INDICATE

- abdominal examination - normal

- midstream urinalysis results - all negative

- post-void residual volume $<100 \mathrm{mls}$

TYPES OF URINARY INCONTINENCE.

This survey focuses on the following conditions:

- stress urinary incontinence

- stress-predominant mixed urinary incontinence

- mixed urinary incontinence (urodynamic stress incontinence with detrusor overactivity) 
Table 1 Patient characteristics and levels captured in the clinical case vignettes

\begin{tabular}{ll}
\hline Characteristics & Level \\
\hline Age group, years & 55 \\
& 68 \\
& 79 \\
BMI $\left(\mathrm{kg} / \mathrm{m}^{2}\right)$ & 23 \\
& 30 \\
Type of stress urinary & 36 \\
incontinence & Pure stress urinary incontinence \\
& Stress-predominant mixed urinary \\
incontinence \\
Previous SUI surgery & Mixed urinary incontinence \\
& None \\
Frequency of leakage & Mid-urethral tape (any route) \\
& Bladder neck injection \\
Bhysical status & About 2 or 3 times a week \\
& About once a day \\
Bother & Several times a day \\
& A bit of a problem \\
& Quite a problem \\
& A serious problem \\
& ASA grade 2 \\
& ASA grade 3 \\
\hline
\end{tabular}

BMI: body mass index; ASA: American Society of Anesthesiologists

\section{PHYSICAL STATUS.}

We describe physical status by the American Society of Anaesthesiologists (ASA grade) classification.

Examples of patients with ASA grade 2

- hypertension: well controlled with one type of antihypertensive medication

- diabetes: well controlled with oral medication or insulin, without diabetic complication

- COPD/asthma: with productive cough and wheeze, well controlled by inhalers with rare episode of acute chest infection, not limiting lifestyle Examples of patients with ASA grade 3

- hypertension: requiring multiple antihypertensive medications or not well controlled

- diabetes: diabetic complications or not well controlled with oral medication or insulin

- COPD/asthma: not well controlled, limiting lifestyle, with high dose of inhaler or oral steroids, with frequent episodes of acute chest infections

The total number of possible different cases that can be generated with the seven identified patient characteristics is $1458\left(=3^{6} \times 2^{1}\right)$ according to a full factorial design. In the third stage ('experimental design'), we used an orthogonal fractional factorial design to reduce the number of clinical case vignettes to 18 using SPSS statistical software [10]. This type of design reduces the number of included vignettes, while maximizing the amount of information collected and retaining the absence of correlation between the patient characteristics [11].
The clinical case vignettes describe the clinical profile of women referred to secondary care for further assessment and management of their SUI. Each case profile consisted of a very short patient description according to the seven characteristics followed by one question: 'Would you recommend that this patient has surgical treatment now?' and the gynaecologists could score their recommendation on a 5point Likert-type scale ranging from 'certainly yes' to 'certainly not'.

\section{Clinical assumptions}

When responding to the clinical case vignettes, the gynaecologists were asked to make two clinical assumptions. First, they had to assume that the women had been referred to secondary care by their general practitioner and had completed all conservative and behavioural treatments without benefit. The second assumption was that the abdominal examination was normal, the midstream urinalysis results were all negative, and post-void residual volume was $<100 \mathrm{ml}$.

\section{Statistical analyses}

The characteristics of the participating gynaecologists were summarized using frequency distributions. We used the means of the response scores and the 25th and 75th percentiles to describe the recommendations of the gynaecologists for each of 18 clinical case vignettes.

To assess the relative influence of the clinical characteristics ('weight') on the gynaecologists' recommendations, we calculated the means of the recommendation score according to the levels of each of the clinical characteristics. The weight of a clinical characteristic was defined as the difference between the lowest and the highest mean recommendation score for that characteristic, divided by the sum of these differences for all seven clinical characteristics [8]. In other words, these weights express as a percentage the influence of each of the seven characteristics on the gynaecologists' recommendations relative to the total overall weight of all characteristics.

We used a mixed-effects analysis of variance model to test the statistical significance of differences in the gynaecologists' recommendation scores according to level of the patient characteristics, taking into account that the recommendation scores for the 18 clinical case vignettes were nested within gynaecologists. The impact of the gynaecologists' background characteristics (main specialty, gender and age) on their recommendations was analysed by testing the interaction between the patient characteristics and gynaecologists' background characteristics with a likelihood ratio test for composite models. We treated the recommendation score as a continuous variable and used parametric statistical methods given that it has been demonstrated that these methods have 
maximum statistical power and are appropriate for analysis of Likert-type data [12].

Latent class analysis is a statistical approach that classifies individuals into mutually exclusive and exhaustive classes based on the pattern of their responses [9]. This statistical approach was used to determine if groups of gynaecologists could be identified whose treatment recommendation scores for each of the 18 case vignettes suggest that they respond to the patient characteristics captured in these case vignettes in a similar way or, in other words, that they have a similar practice style.

Gynaecologists who were classed within the same group are expected to be more homogeneous with respect to their recommendation scores than gynaecologists classed in different groups. The Aikaike information criteria (AIC) and the Bayesian information criteria (BIC) were used to determine the optimal number of latent classes.

The predicted posterior probabilities of latent class membership were used to assign each gynaecologist in a group. In case a gynaecologist did not have a posterior probability $>$ $50 \%$ for one particular group, group membership was considered to be unknown.

All statistical analyses were performed using Stata 15 [13].

The project was funded by the National Institute for Health Research (NIHR) Health Services and Delivery Research (HS\&DR) Programme (14/70/162) in response to a peerreviewed application. Two lay members of the project advisory team advised on the conduct of the the study design and the interpretation of results. The funder had no role in the design and conduct of the study; collection, management, analysis and interpretation of the data; preparation, review or approval of the manuscript; and decision to submit the manuscript for publication.

\section{Results}

Three hundred thirty-four gynaecologists participated in the survey, of which 245 (73.4\%) fully completed the questionnaire (Supporting Information, Fig. S1). Of the 245 gynaecologists, $56.3 \%$ were male, while $55.9 \%$ indicated urogynecology as their main specialty area (Table 2 ).

\section{Recommendations for surgery}

Figure 1 shows the extent of variation in the recommendation scores of all gynaecologists for the 18 case profiles. The interquartile range was between 2 and 4 on the 5-point scale for 11 of the 18 vignettes. The scores were most strongly in favour of recommending surgery for case 5 (a 68 -year-old woman with BMI of 30, with pure SUI, without previous SUI surgery, with leakage several times a day, for whom the incontinence is quite a problem and with an ASA of 2) and most strongly
Table 2 Characteristics of gynaecologists and mean recommendation scores

\begin{tabular}{lccl}
\hline Characteristics & Number & $\%$ & $\begin{array}{l}\text { Mean recommendation } \\
\text { score (standard } \\
\text { deviation) }\end{array}$ \\
\hline $\begin{array}{l}\text { Total } \\
\text { Gender }\end{array}$ & 245 & 100 & $2.87(1.28)$ \\
Female & 106 & 43 & $2.88(1.26)$ \\
Male & 139 & 57 & $2.86(1.30)$ \\
Age categories & & & \\
$<45$ years & 85 & 35 & $2.88(1.27)$ \\
45-54 years & 84 & 34 & $2.87(1.30)$ \\
$\geq 55$ years & 76 & 31 & $2.85(1.27)$ \\
Clinical specialty & & & \\
Gynaecology & 108 & 44 & $2.83(1.27)$ \\
Urogynecology & 137 & 56 & $2.90(1.29)$ \\
Trainee & & & \\
No & 212 & 87 & $2.86(1.29)$ \\
Yes & 33 & 13 & $2.91(1.24)$ \\
Region of practice in the UK & & $2.86(1.28)$ \\
England & 212 & 87 & $2.75(1.13)$ \\
Northern Ireland & 11 & 4 & $3.03(1.34)$ \\
Scotland & 15 & 6 & $2.90(1.34)$ \\
Wales & 7 & 3 & \\
\hline
\end{tabular}

*Mean score on a 5-point scale ranging from $1=$ "certainly not" to $5=$ "certainly yes"

against recommending surgery for case 6 (a 68 -year-old woman with BMI of 23, with MUI, with previous SUI surgery, with leakage one a day, for whom the incontinence is a bit of a problem and with ASA of 3).

\section{Impact of women's characteristics on gynaecologists' recommendations}

Figure 2 demonstrates the impact of the patient characteristic on the gynaecologists' recommendations. Overall, the impact of the patient characteristics was relatively small. The nature of the urinary incontinence had the greatest impact with a mean difference in the recommendation score for women with SUI and MUI of 0.8 , which corresponds to a weight of $23 \%$ (see Methods), closely followed by the impact of a woman's previous history of SUI surgery (weight of 21\%) and - albeit it to a lesser extent - the frequency of urinary leakage (weight of $15 \%$ ), BMI status (weight of 15\%) and bother (weight of $13 \%$ ). A woman's physical status (weight of $8 \%$ ) and her age (weight of 6\%) had the least influence on the gynaecologists' recommendations. The results of the mixed-effects analysis of variance indicated that all clinical characteristics captured in the case vignettes significantly influenced the recommendation score ( $p$ always $<0.001$ ). 


\begin{tabular}{|c|c|c|c|c|c|c|}
\hline Case & Age & $\mathrm{BMI}$ & Type of UI & Previous SUI Surgery & Leakage & Bother \\
\hline 1 & 55 & 36 & MUI & MUT & several times a day & a serious problem \\
\hline 2 & 79 & 36 & sul & MUT & about 2 or 3 times a week & quite a problem \\
\hline 3 & 68 & 36 & Stress-predominant MUI & $\mathrm{BNI}$ & about 2 or 3 times a week & a serious problem \\
\hline 4 & 55 & 23 & Stress-predominant MUI & MUT & several times a day & quite a problem \\
\hline 5 & 68 & 30 & sul & None & several times a day & quite a problem \\
\hline 6 & 68 & 23 & MUI & MUT & about once a day & a bit of a problem \\
\hline 7 & 79 & 23 & sul & $\mathrm{BNI}$ & several times a day & a serious problem \\
\hline 8 & 79 & 36 & MUI & None & about once a day & quite a problem \\
\hline 9 & 55 & 36 & sul & $\mathrm{BNI}$ & about once a day & a bit of a problem \\
\hline 10 & 79 & 30 & MUI & $\mathrm{BNI}$ & several times a day & a bit of a problem \\
\hline 11 & 55 & 30 & MUI & None & about 2 or 3 times a week & a serious problem \\
\hline 12 & 79 & 30 & Stress-predominant MUI & MUT & about 2 or 3 times a week & a bit of a problem \\
\hline 13 & 55 & 23 & sul & None & about 2 or 3 times a week & a bit of a problem \\
\hline 14 & 68 & 30 & sul & MUT & about once a day & a serious problem \\
\hline 15 & 55 & 30 & Stress-predominant MI & $\mathrm{BNI}$ & about once a day & quite a problem \\
\hline 16 & 68 & 36 & Stress-predominant MUI & None & several times a day & a bit of a problem \\
\hline 17 & 79 & 23 & Stress-predominant MUI & None & about once a day & a serious problem \\
\hline 18 & 68 & 23 & MUI & $\mathrm{BNI}$ & about 2 or 3 times a week & quite a problem \\
\hline
\end{tabular}

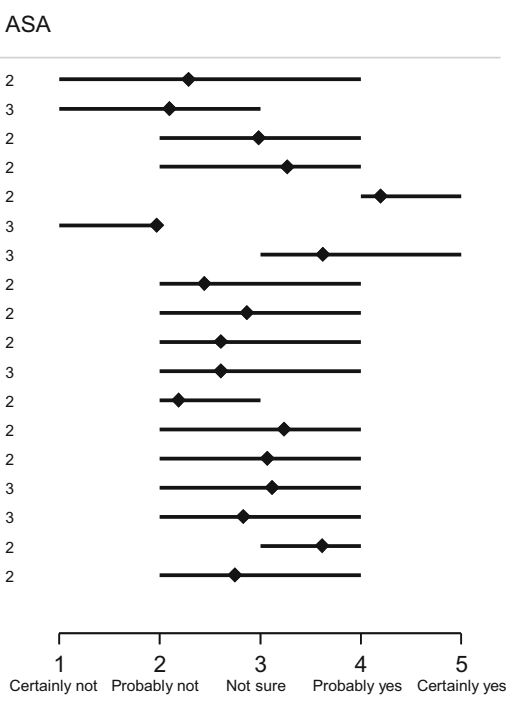

Fig. 1 Surgical treatment recommendations of the gynaecologists for 18 clinical case vignettes. The range plots (horizontal bars) represent the 25 th and 75 th percentile and the mean of the recommendation score. SUI,

\section{Impact of gynaecologists' characteristics on their recommendations}

The average recommendation scores did not differ significantly according to the gynaecologists' gender, age, specialty and trainee status (Table 2). In addition, there were no statistically significant differences between the stress urinary incontinence; MUI, mixed urinary incontinence; BNI, bladder neck injection; MUT, mid-urethral tape; BMI, body mass index in $\mathrm{kg} / \mathrm{m}^{2}$; ASA, American Society of Anesthesiologists

scores of gynaecologists based in England, Scotland, Wales and Northern Ireland.

We did not find any evidence that the weights or relative influence of the patient characteristics on the recommendation scores varied according to the gynaecologists' background characteristics on their recommendations ( $p$ value of interaction test for specialty, gender and age always $>0.05$ ).

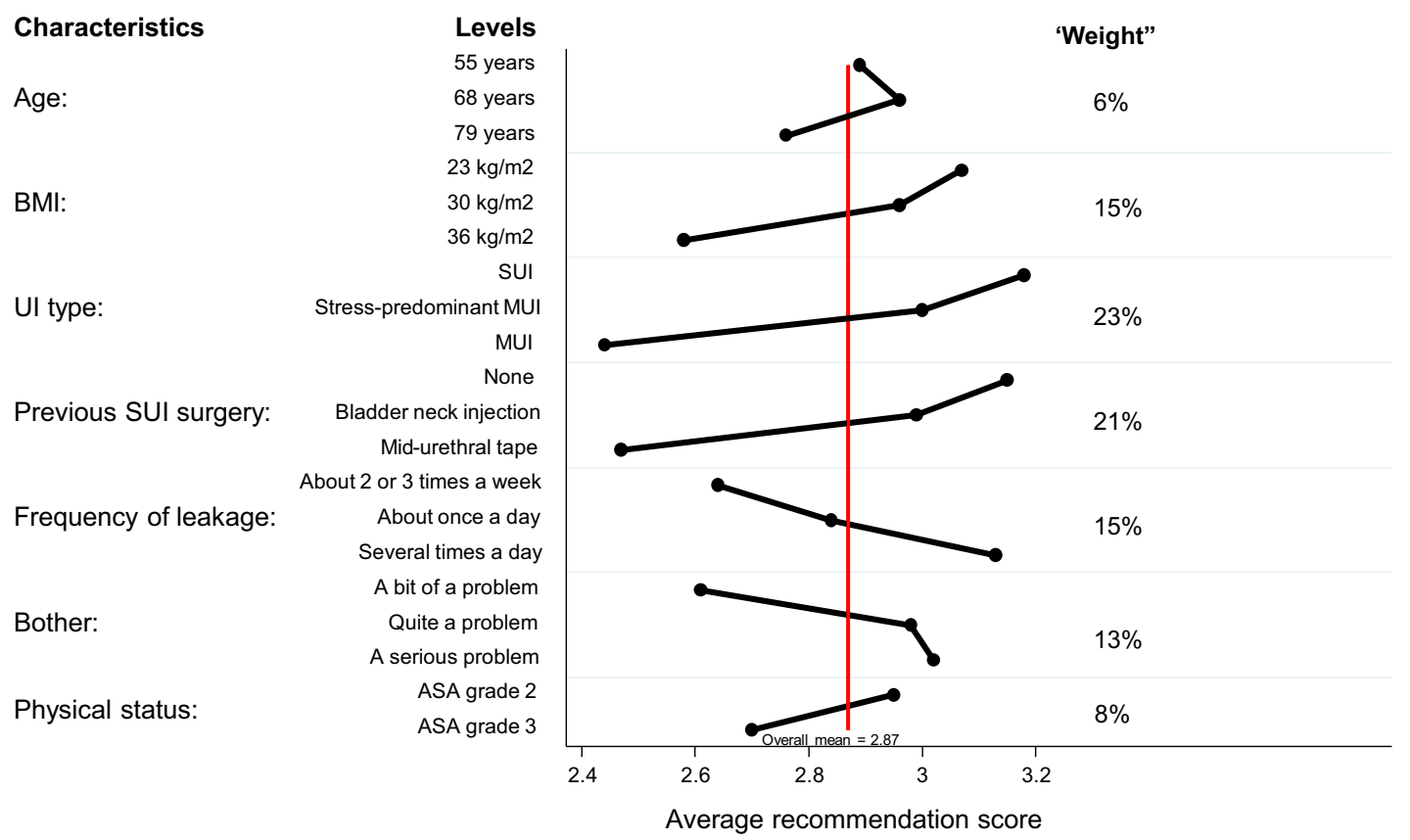

Fig. 2 Influence of patient characteristics on gynaecologists' recommendations for surgical treatment on a 5-point scale ranging from 1 'certainly not' to 5 'certainly yes'. SUI, stress urinary incontinence;
MUI, mixed urinary incontinence; BMI, body mass index in $\mathrm{kg} / \mathrm{m}^{2}$ ); ASA, American Society of Anesthesiologists 
Additional analyses found that six gynaecologists consistently gave a recommendation score of 1 ('certainly not') to all 18 clinical case vignettes. Excluding the responses of these six gynaecologists had only a slight impact on the mean recommendation scores or the weights of the patient characteristics.

\section{Gynaecologists' practice styles}

The results of the latent class analysis indicated that five mutually exclusive groups of gynaecologists could be identified with a different practice style (Fig. 3). The AIC and BIC both continued to go down as more latent classes were added, but there was a levelling off beyond a solution with five latent classes. Two hundred forty-four of the 245 respondents could be assigned to a particular group (see Methods).

The mean recommendation scores for the five practice style groups ranged from 1.25 to 4.04 ( $p<0.001$ ), which demonstrates a wide variation in the gynaecologists' average inclination to recommend surgical treatment (Table 3). There were no significant differences in the gynaecologists' characteristics between the groups.

The impact of the women's characteristics on gynaecologists' recommendation scores is small compared with the differences in their average inclination to recommend surgical treatment among the five practice style groups. The impact of the women's characteristics on the recommendation scores is relatively consistent (Fig. 3). The largest differences can be observed in the recommendations of the gynaecologists in group 2 and group 3, who seemed to give a greater weight to the BMI, type of UI and previous SUI surgery than the gynaecologists in the other groups.

\section{Discussion}

\section{Main findings}

Our nation-wide survey among UK gynaecologists with a special interest in urogynecology demonstrated wide variation in the recommendations given to a series of hypothetical patients. We could distinguish five groups of gynaecologists whose practice style differed widely with respect to their average inclination to recommend surgical treatment. In addition, we found that gynaecologists' recommendations for surgical treatment were only minimally influenced by patient characteristics with type of UI and whether women had previously undergone surgical treatment having the greatest impact. Lastly, the gynaecologists' recommendation scores did not seem to vary according to their gender, age, whether they indicated urogynecology as their sub-specialty status or their training status.

\section{Comparison with other studies}

We observed that the impact of the patient characteristics was relatively small. An explanation for the slightly larger weights given to the type of UI and previous SUI surgery may be that these patient characteristics have been recognized as risk

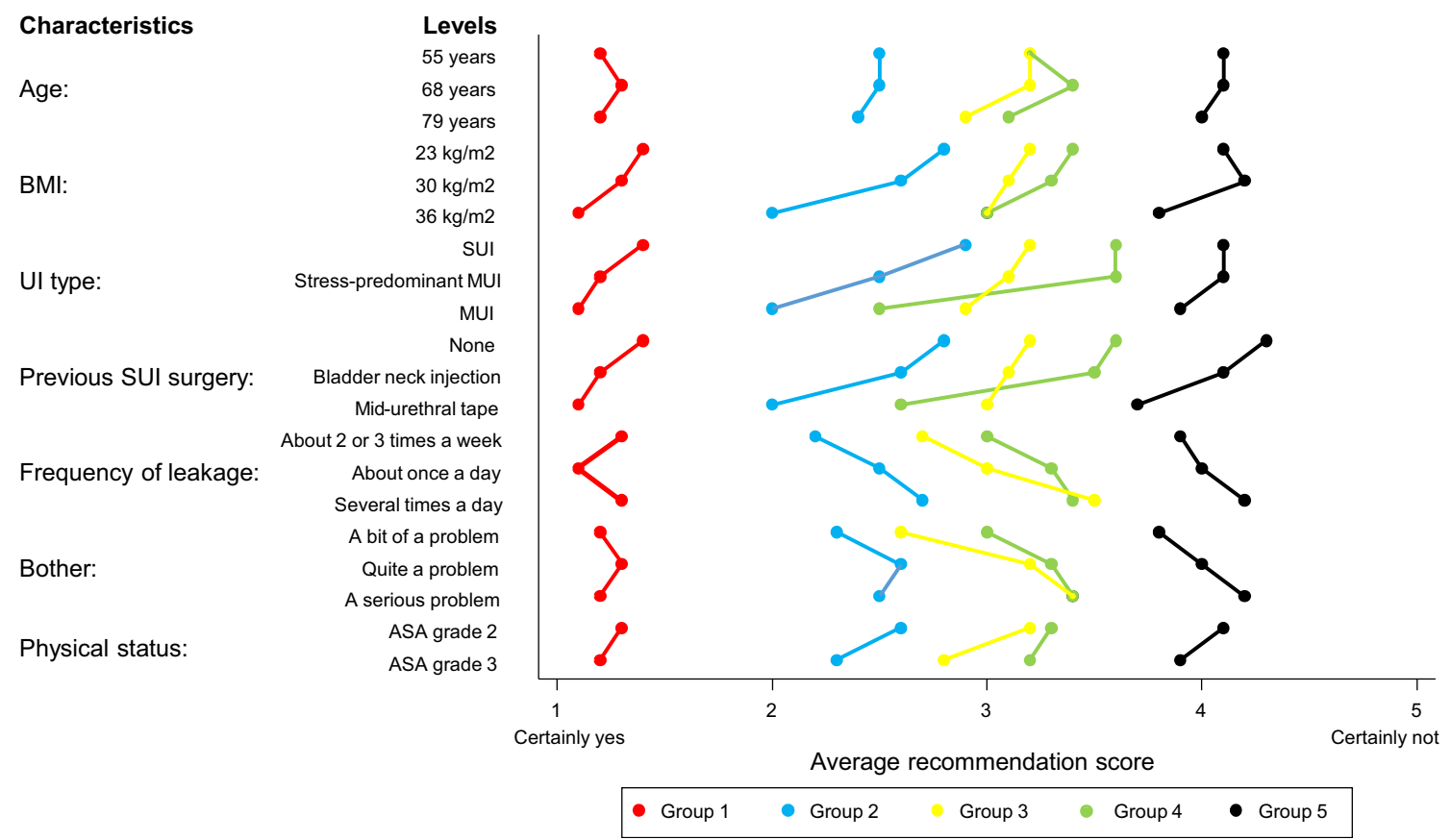

Fig. 3 Influence of patient characteristics on gynaecologists' recommendations for surgical treatment on a 5-point scale according to practice style group. SUI, stress urinary incontinence; MUI, mixed urinary incontinence; BMI, body mass index in $\mathrm{kg} / \mathrm{m}^{2}$; ASA, American Society of Anesthesiologists 
Table 3 Characteristics of gynaecologists according to their practice style group derived from the latent class analysis (numbers and percentages unless otherwise indicated)

\begin{tabular}{|c|c|c|c|c|c|c|c|}
\hline Characteristics & All & Group 1 & Group 2 & Group 3 & Group 4 & Group 5 & $P$ value \\
\hline & 244 & 17 & 85 & 52 & 69 & 21 & \\
\hline Mean recommendation score* & 2.87 & 1.25 & 2.47 & 3.10 & 3.24 & 4.04 & $<0.001$ \\
\hline Gender & & & & & & & 0.77 \\
\hline Female & $105(43.0 \%)$ & $6(35.3 \%)$ & $41(48.2 \%)$ & $22(42.3 \%)$ & $27(39.1 \%)$ & $9(42.9 \%)$ & \\
\hline Age categories & & & & & & & 0.60 \\
\hline$<45$ years & $71(29.1 \%)$ & $4(23.5 \%)$ & $28(32.9 \%)$ & $11(21.2 \%)$ & $23(33.3 \%)$ & $5(23.8 \%)$ & \\
\hline $45-54$ years & $97(39.8 \%)$ & $10(58.8 \%)$ & $30(35.3 \%)$ & $24(46.2 \%)$ & $24(34.8 \%)$ & $9(42.9 \%)$ & \\
\hline$\geq 55$ years & $76(31.1 \%)$ & $3(17.7 \%)$ & $27(31.8 \%)$ & $17(32.7 \%)$ & $22(31.9 \%)$ & $7(33.3 \%)$ & \\
\hline Clinical specialty & & & & & & & 0.14 \\
\hline Gynaecology & $107(43.9 \%)$ & $5(29.4 \%)$ & $43(50.6 \%)$ & $19(36.5 \%)$ & $34(49.3 \%)$ & $6(28.6 \%)$ & \\
\hline Urogynecology & $137(56.1 \%)$ & $12(70.6 \%)$ & $42(49.4 \%)$ & $33(63.5 \%)$ & $35(50.7 \%)$ & $15(71.4 \%)$ & \\
\hline Trainee & & & & & & & 0.55 \\
\hline Yes & $33(13.5 \%)$ & $1(88.2 \%)$ & $10(11.8 \%)$ & $7(13.5 \%)$ & $13(18.8 \%)$ & $2(9.5 \%)$ & \\
\hline
\end{tabular}

*Mean score on a 5-point scale ranging from $1=$ "certainly not" to 5 = "certainly yes"

factors for a poor postoperative outcome [14]. This observation is also in line with results from a study, based on a survey of members of the International Urogynaecological Association, highlighting that clinical decisions in the management of recurrent SUI are guided by the type of previous surgery, urodynamic findings and individual surgeon's preference [15].

The uniformity of the training of surgeons in the UK as well as the clinical governance structure in place in the UK's National Health Service may explain why neither the surgeons' demographic characteristics nor their main specialty or training status had an impact on how they responded to the patient characteristics represented in the clinical case vignettes. However, these results are in contrast with a number of recent clinician surveys. For example, a recent study involving general gynaecologists in the USA found their age to be a determinant of the surgical treatment options they offered [16]. Younger gynaecologists tended to have a smaller repertoire of surgical procedures than older gynaecologists. Similarly, a recent survey of UK specialists on how they managed recurrent or persistent SUI after the failure of primary surgery treatment demonstrated that training and the surgeons' skills and experience played a vital role in their decisionmaking [17].

We observed that a woman's age and BMI had relatively little impact on the gynaecologists' recommendations for surgical treatment. This corresponds to an increasing body of evidence indicating that surgical treatments are effective in obese and in elderly patients [18-22]. On the other hand, it is also generally accepted that clinical decision-making is more complex given that overall health and functional status is poorer in these patient groups [21]. For example, it has recently been reported in a study of 12,000 women in the
UK that an increased BMI is associated with poorer results of incontinence surgery according to outcomes reported by women themselves [23].

\section{Interpretation}

Our study using case vignettes focused on the extent to which the gynaecologists' recommendations for surgical treatment for women with SUI depend on patient characteristics. In clinical practice, however, women's actual decisions about whether or not to undergo surgery will be informed by the recommendations from their gynaecologists as well as by their own preferences for treatment.

In the clinical case vignettes, we included patient characteristics that can only be derived from patient-reported information (frequency of leakage and bother) and those that are derived from information determined by the clinicians (type and severity of UI, previous surgery). We found that the weights assigned to the latter two (the clinician-derived characteristics) had a stronger combined influence on the gynaecologists' recommendations than the patient-reported characteristics. It is important to note that the clinicianderived characteristics describe the severity and type of the urinary incontinence that have a recognized impact on the effectiveness of specific surgical treatments.

Most importantly, the results of our survey have to be interpreted in the light of the ongoing debate and increasing concerns about the safety of mid-urethral mesh tape procedures for women with SUI and the simultaneous rapid decline in the use of mid-urethral tape insertion as a treatment for SUI [2]. The large variation in the average inclination to recommend surgery among the five groups of gynaecologists that we could identify based on their practice style is likely to 
correspond to the substantial geographical variation that we demonstrated in the rate of SUI surgery in the English NHS between 2013 and 2016 [24]. This study, based on administrative hospital data, found a four-fold variation in the rate of surgery for SUI among 44 regional areas, each including on average about 500,000 adult women, set up to coordinate improvement of services in the English NHS.

Clinical uncertainty about the safety of using mid-urethral mesh tape insertions as well as fear of potential litigation is a likely explanation for both the variation in the average inclination among the five recognized practice style groups as well as the differences in rates of surgical treatment between the geographical areas [6]. The wide variation in practice style observed in our survey may also have medicolegal implications given that it can be argued that a clinician is not negligent if he or she acts in accordance with a practice accepted at the time as proper, even though some other clinicians adopt a different practice [25].

\section{Strengths and limitations}

To our knowledge, our study is the second example of research using clinical case vignettes to investigate the extent to which specific patient characteristics influence gynaecologists' treatment recommendations for women with urinary incontinence [6]. A strength of our study is that we invited all members of two professional bodies, practicing in the UK, who had indicated a specialist interest in urinary incontinence.

Of the 1139 gynaecologists who were invited to participate, only 245 fully responded. An additional analysis, comparing the characteristics of the gynaecologists who fully completed the survey with the 334 who only submitted partially completed surveys, did not show statistically significant differences in their characteristics (gender, age, specialty and training status), which - albeit indirectly - provides some evidence for the representativeness of the gynaecologists that fully responded to our survey. It has to be noted, however, that clinicians whose main specialty is urology were not included and their practice and views may be different. As a result, our findings are only applicable to gynaecological practice.

The validity of conjoint analysis as an experimental approach to get a better understanding of how clinicians respond to clinical cues is well established [26, 27]. This technique is frequently used to elicit views of health practitioners on the desirability of particular treatment options [5, 28]. An important example supporting the validity of conjoint analysis is a study comparing decisions to recommend surgery made in response to clinical case vignettes - very similar to those used in the current study - and those made for actual patients with aortic stenosis [29], which showed strong agreement in the way that that clinicians responded to the clinical characteristics captured in the clinical case vignettes and those for actual patients.
The use of conjoint analysis required that the recommendations of the clinicians for each case vignette were captured on a unidimensional scale (recommendation for surgery ranging from 'certainly yes' to 'certainly not'). As a result, we were not able to include different alternatives for surgical treatment in the vignettes. In the UK, these alternatives may include continence tampons but not pessaries as the latter are not included as a recommended treatment option for urinary incontinence in recent UK guidelines [1]. Our results clearly demonstrate however that in the UK a considerable number of gynaecologists with a specialist interest in urogynecology are reluctant to recommend surgical treatment for women with urinary incontinence who have completed all conservative and behavioural treatments without benefit.

\section{Conclusions}

In the UK, surgical decision-making for female SUI was most strongly influenced by the type of UI and previous SUI surgery. We found five groups of gynaecologists with different practice styles, mainly related to their average inclination to recommend surgery. This demonstrated that there is a lack of consensus on the role of surgery as a treatment option for SUI, which may correspond to the clinical uncertainty about the safety of incontinence surgery using mid-urethral mesh tape insertions.

Acknowledgements We acknowledge the support we received from members of the British Society of Urogynaecology and the Royal College of Obstetricians and Gynaecologists who participated in the survey. We would like to thank James Cross for administering the survey.

Authors' participation Protocol/project development: Mamza, Geary, ElHamamsy, Gurol-Urganci, Duckett, Mahmood, Monga, Toozs-Hobson, Wilson, Tincello, Van der Meulen.

Data collection: Mamza.

Data analysis: Mamza with support from Van der Meulen.

Manuscript writing: Mamza wrote the first draft of the manuscript with contributions from Geary, El-Hamamsy, Gurol-Urganci, Duckett, Mahmood, Monga, Toozs-Hobson, Wilson, Tincello, Van der Meulen.

Joint senior authors and guarantors: Tincello and Van der Meulen.

Funding National Institute for Health Research (NIHR) Health Services and Delivery Research (HS\&DR) Programme (14/70/162).

\section{Compliance with ethical standards}

Details of ethics approval Not required for a survey conducted on members of professional bodies.

Conflict of interest Monga acted as consultant for Contura and Atlantic Therapeutics and as medicolegal expert for Kennedys Law and Clyde and Co. Toozs-Hobson has acted as a consultant for Boston Scientific and Contura. Tincello acted consultant for Cambridge Medical Robotics, Femeda and Astellas. All other authors declare no competing interests. 
Open Access This article is licensed under a Creative Commons Attribution 4.0 International License, which permits use, sharing, adaptation, distribution and reproduction in any medium or format, as long as you give appropriate credit to the original author(s) and the source, provide a link to the Creative Commons licence, and indicate if changes were made. The images or other third party material in this article are included in the article's Creative Commons licence, unless indicated otherwise in a credit line to the material. If material is not included in the article's Creative Commons licence and your intended use is not permitted by statutory regulation or exceeds the permitted use, you will need to obtain permission directly from the copyright holder. To view a copy of this licence, visit http://creativecommons.org/licenses/by/4.0/.

\section{References}

1. National Institute for Health and Care Excellence (NICE) (2019) Urinary incontinence and pelvic organ urinary incontinence and pelvic organ prolapse in women: management prolapse in women: management (NG123). National Institute for Health and Care Excellence

2. Gurol-Urganci I, Geary RS, Mamza JB, Duckett J, El-Hamamsy D, Dolan L, et al. Long-term rate of mesh sling removal following midurethral mesh sling insertion among women with stress urinary incontinence. JAMA. 2018;320(16):1659-69. https://doi.org/10. 1001/jama.2018.14997.

3. Digital NHS. Hospital Episode Statistics. England: Patient admitted care; 2018. https://digital.nhs.uk/data-and-information/ publications/statistical/hospital-admitted-patient-care-activity

4. National Institute for Health and Care Excellence (NICE) (2019) Urinary incontinence and pelvic organ prolapse in women: management.

5. Bachmann LM, Muhleisen A, Bock A, ter Riet G, Held U, Kessels AG. Vignette studies of medical choice and judgement to study caregivers' medical decision behaviour: systematic review. BMC Med Res Methodol 2008;8(50).

6. Kessler TM, Maric A, Mordasini L, Wollner J, Pannek J, Mehnert U, et al. Urologists' referral attitude for sacral neuromodulation for treating refractory idiopathic overactive bladder syndrome: discrete choice experiment. Neurourol Urodyn 2014;33(8):1240-6. https:// doi.org/10.1002/nau.22490.

7. Wigton RS, Hoellerich VL, Patil KD. How physicians use clinical information in diagnosing pulmonary embolism: an application of conjoint analysis. Med Decision Making: Int J Soc Med Dec Making. 1986;6(1):2-11. https://doi.org/10.1177/0272989x8600600102.

8. Green PE, Srinivasan V. Conjoint analysis in consumer research: issues and outlook. J Consum Res 1978;5(2):103-23.

9. Collins L, Lanza ST (2010) Latent Class and Latent Transition Analysis: With Applications in the Social, Behavioural, and Health Sciences. Wiley Series in Probability and Statistics. John Wiley \& Sons, Hoboken, NJ.

10. Louviere JJ, Hout M (1988) Anal decision making: Metric conjoint analysis. Vol 67. Sage

11. Gustafsson A, Herrmann A, Huber F (2007) Conjoint measurement: methods and applications.

12. Norman G. Likert scales, levels of measurement and the "laws" of statistics. Adv Health Sci Educ 2010;15(5):625-32.

13. StataCorp. Stata Statistical Software: Release 15. College Station, TX: StataCorp LLC; 2017.

14. Stav K, Dwyer PL, Rosamilia A, Schierlitz L, Lim YN, Lee J. Risk factors of treatment failure of midurethral sling procedures for women with urinary stress incontinence. Int Urogynecol J 2010;21(2):149-55. https://doi.org/10.1007/s00192-009-1020-9.
15. Giarenis I, Thiagamoorthy G, Zacche M, Robinson D, Cardozo L. Management of recurrent stress urinary incontinence after failed midurethral sling: a survey of members of the International Urogynecological Association (IUGA). Int Urogynecol J Pelvic Floor Dysfunct 2015;26(9):1285-91.

16. Yune JJ, Siddighi S. Perceptions and practice patterns of general gynaecologists regarding urogynecology and pelvic reconstructive surgery. Female Pelvic Med Reconstructive Surg. 2013;19(4):2259. https://doi.org/10.1097/SPV.0b013e3182995107.

17. Tincello DG, Armstrong N, Hilton P, Buckley B, Mayne C. Surgery for recurrent stress urinary incontinence: the views of surgeons and women. Int Urogynecol J 2018;29(1):45-54. https://doi.org/10. 1007/s00192-017-3376-6.

18. Rogers RG, Lebkuchner U, Kammerer-Doak DN, Thompson PK, Walters MD, Nygaard IE. Obesity and retropubic surgery for stress incontinence: is there really an increased risk of intraoperative complications? Am J Obstet Gynecol 2006;195(6):1794-8. https://doi. org/10.1016/j.ajog.2006.07.012.

19. Rechberger T, Futyma K, Jankiewicz K, Adamiak A, Bogusiewicz M, Skorupski P. Body mass index does not influence the outcome of anti-incontinence surgery among women whereas menopausal status and ageing do: a randomized trial. Int Urogynecol $\mathrm{J}$ 2010;21(7):801-6. https://doi.org/10.1007/s00192-010-1116-2.

20. Ellington DR, Erekson EA, Richter HE. Outcomes of surgery for stress urinary incontinence in the older woman. Clin Geriatr Med 2015;31(4):487-505. https://doi.org/10.1016/j.cger.2015.06.006.

21. Ellington DR, Ballard AC. Surgical treatment and outcomes for the management of stress urinary incontinence in the older woman. Current Geriatrics Reports. 2017;6(2):90-7. https://doi.org/10. 1007/s13670-017-0204-2.

22. Franzen K, Andersson G, Odeberg J, Midlov P, Samuelsson E, Stenzelius K, et al. Surgery for urinary incontinence in women 65 years and older: a systematic review. Int Urogynecol J 2015;26(8): 1095-102. https://doi.org/10.1007/s00192-014-2573-9.

23. Bach F, Hill S, Toozs-Hobson P. The effect of body mass index on retropubic midurethral slings. Am J Obstet Gynaecol. 2019;220(4): 371.e371-9. https://doi.org/10.1016/j.ajog.2018.12.018.

24. Mamza JB, Geary RS, El-Hamamsy D, Cromwell DA, Duckett J, Monga A, et al. Geographical variation in rates of surgical treatment for female stress urinary incontinence in England: a national cohort study. BMJ Open. 2019;9(8):e029878. https://doi.org/10.1136/ bmjopen-2019-029878.

25. Foster C. Civil procedure, trial issues and clinical guidelines. Clin Guidelines: Law, Policy Pract. 2002.

26. Ryan M, Farrar S. Using conjoint analysis to elicit preferences for health care. BMJ: British Med J. 2000;320(7248):1530-3.

27. Lancsar E, Louviere J, Flynn T. Several methods to investigate relative attribute impact in stated preference experiments. Social Sci Med. 2007;64(s):1738-53. https://doi.org/10.1016/j.socscimed.2006.12.007.

28. Engel J, van der Wulp I, Poldervaart JM, Reitsma JB, de Bruijne MC, Wagner C. Clinical decision-making of cardiologists regarding admission and treatment of patients with suspected unstable angina or non-ST-elevation myocardial infarction: protocol of a clinical vignette study. BMJ Open. 2015;5(4):e006441. https://doi.org/10. 1136/bmjopen-2014-006441.

29. Bouma BJ, van der Meulen JH, van den Brink RB, Smidts A, Cheriex EC, Hamer HP, et al. Validity of conjoint analysis to study clinical decision making in elderly patients with aortic stenosis. J Clin Epidemiol 2004;57(8):815-23. https://doi.org/10.1016/j. jclinepi.2003.12.014.

Publisher's note Springer Nature remains neutral with regard to jurisdictional claims in published maps and institutional affiliations. 